\title{
LA SEMIÓTICA EN GALICIA: LA ASOCIACIÓN GALLEGA DE SEMIÓTICA
}

\author{
José María Paz Gago y Pilar Couto Cantero \\ Universidade da Coruña
}

\section{INICIO}

En el presente trabajo se expone la historia de la investigación semiótica en Galicia desde sus orígenes, a principios de los años setenta, cuando llega a la Universidad de Santiago la profesora Bobes Naves, quien en 1973 publica La semiótica como teoría lingüística. El primer resultado de la incipiente semiótica literaria gallega va a ser el volumen colectivo Crítica Semiológica, publicado en 1974 por la Universidad santiaguesa. Un buen grupo de discípulos directos e indirectos de Bobes Naves hacen surgir en la Universidad Compostelana un importante centro de Semiótica literaria formado por investigadores entre los que destacan Darío Villanueva, Anxo Tarrío, Xosé Anxo Fernández Roca, Alberto Álvarez Sanagustín o Rafael Núñez Ramos.

En la actualidad funcionan en la Comunidad Autónoma Gallega tres centros principales de investigación semiótica, vinculados a las tres 
Universidades de Galicia: El Grupo de la Universidad de Santiago de Compostela, dirigido por Darío Villanueva, encuentra su especificidad en un componente fuertemente fenomenológico y hermenéutico que lo vincula a la Semiótica peirceana; en la Universidad de La Coruña trabaja un activo grupo que, directamente vinculado a la semiótica peirceana y a la obra de Bobes Naves, despliega también una intensa actividad científica que se refleja en congresos, seminarios y diversas publicaciones; por último, la investigación semiótica en la Universidad de Vigo compendia y sintetiza esas mismas bases teóricas, la Fenomenología Compostelana y la Semiótica literaria de Carmen Bobes.

\section{LOS ORÍGENES DE LA INVESTIGACIÓN SEMIOLÓGICA EN GALICIA}

En la segunda mitad de los años sesenta, la profesora Carmen Bobes Naves redacta la que será una de las primeras y más sólidas investigaciones en el ámbito semiótico hispánico. En La semiótica como teoría lingüística, trabajo publicado en 1973, proponía su autora un método semiológico para el análisis no sólo de la lengua y la literatura, sino de cualquier otro sistema de signos (cf. Bobes 1994: 11), convirtiéndose así en la pionera de la investigación semiótica en España. A principios de la década siguiente, la profesora Bobes Naves llega a la entonces única Universidad de Galicia, surgiendo así un importante núcleo semiológico en la Universidad de Santiago de Compostela, fundamentalmente vinculado a la Facultad de Filosofía y Letras, donde a su intenso magisterio se unen las orientaciones estructuralistas de otros profesores de Literatura y Linguiística.

Desde los años sesenta, Benito Varela Jácome (1967, 1973 y 1974) lleva a cabo un estudio estructural de la narrativa contemporánea muy avanzado para su época, perspectiva formalista que se va acercando a los postulados semióticos, especialmente de inspiración greimasiana (1973: 75-77) o, más tarde, lotmaniana (1980). Introductor de una formalización semiológica muy útil para fines didácticos, mediante diagramas y esquemas funcionales, al contacto con los trabajos de Carmen Bobes, elabora un método sincrético de análisis (1980 y 1989) en el que integra las aportaciones del primer Greimas, del formalismo ruso y francés así como de la Escuela de Tartu, tal como la había introducido Mignolo entre nosotros. 
El primer resultado de la incipiente investigación gallega en semiótica literaria va a ser el volumen colectivo Crítica Semiológica (Bobes, ed., 1974), publicado por la Universidad Compostelana, con una larga introducción en la que la editora del volumen expone las bases teóricas de la Crítica literaria de orientación semiológica: el formalismo ruso, el estructuralismo lingüístico, la Lógica Neopositivista y el Pragmatismo norteamericano divulgado por Morris. De este modo, la Doctora Bobes Naves expone ampliamente los aspectos sistemáticos y analíticos de un método que tendrá un amplio eco en la enseñanza secundaria y universitaria española y gallega.

Colabora en ese volumen un grupo de jóvenes profesores gallegos como Joaquina Canoa Galiana, Alberto Álvarez Sanagustín o Rafael Núñez Ramos, a los que se añadirán, en una segunda edición, María Dolores Rajoy Feijóo y Antonio Gil Hernández, además de otros jóvenes estudiosos que en España comenzaban a destacar en los estudios semióticos, como José Romera Castillo. A este primer núcleo formado directamente por la profesora Bobes Naves, hay que añadir otros investigadores que participan en sus Cursos de Doctorado y adoptan las bases de su metodología entonces muy innovadora: Darío Villanueva, Xosé Anxo Fernández Roca, Miguel Gómez Segade, etc.

Cuando en la segunda mitad de la década, Carmen Bobes abandona Santiago para incorporarse a la Universidad de Oviedo con buena parte de sus discípulos más destacados para fundar el Grupo Semiológico de Oviedo, la Universidad Compostelana de los años setenta y ochenta se ha convertido ya en un importante centro de investigaciones en Semiótica literaria.

Darío Villanueva (1977), que ya empieza a destacar por su inteligencia y agudeza crítica, lleva a cabo una sólida investigación sobre la estructura temporal de la novela contemporánea que, partiendo de bases distintas, se sitúa en un perfecto paralelismo con las aportaciones más solventes de la narratología francesa. Continuando esa línea de investigación, desarrolla una teoría de la recepción de la novela picaresca (1986) cuyas conclusiones presenta en Madrid en el Congreso Internacional sobre Semiótica e Hispanismo, foro de gran valor histórico para la semiótica hispánica, organizado por el profesor Garrido Gallardo bajo los auspicios del Consejo Superior de Investigaciones Científicas, que servirá de marco para la fundación de la Asociación Española de Semiótica. Sus estudios de narrativa (1991b, 1992a) le llevarán a construir una teoría del realismo literario de gran alcance, convirtiéndole en maestro indiscutible de la Semiótica en Galicia. 
En ese mismo contexto, Anxo Tarrío Varela, hoy catedrático de Literatura Galega en Santiago, escribe bajo la dirección de Carmen Bobes su tesis doctoral sobre la novelística de Galdós, obra que aparecerá en 1982 con el título Lectura semiológica de Fortunata y Jacinta. Sus análisis semióticos sobre la literatura y la realidad gallega son publicados poco más tarde en De letras e de signos. Ensaios de Semiótica e Crítica literatia (1987).

Si Benito Varela Jácome, como ya hemos dicho pionero en este tipo de trabajos, divulga un método muy pedagógico de análisis semiológico de textos literarios aplicado a la narrativa española, gallega e hispanoamericana, los estudios de Literatura Gallega conocen un gran florecimiento, de la mano de un autodidacta que conoce bien la Poética estructuralista de origen francés, Carballo Calero. Sus estudios estructuralistas strictu sensu sobre novela, poesía y teatro significan la incorporación de las nuevas metodologías al estudio crítico e histórico de la literatura gallega. que tendrán una continuidad asegurada en discípulos como Araceli Herrero Figueroa.

\section{LA SEMIÓTICA Y LA CULTURA GALLEGA}

La aplicación de la metodología semiótica a la cultura nacional gallega, en todas sus manifestaciones lingüísticas y artísticas, literarias o cinematográficas, ha llevado también a configurar un importante corpus de investigaciones. La Semiótica de la cultura, la Semiología literaria y la visual encuentran un campo específico de aplicación en una determinación geográfica, histórica, lingüística y cultural tan precisa como Galicia, marco en el que los fenómenos sígnicos y comunicacionales responden a ese contexto espacial específico en que han sido producidos y en el que se sitúan sus eventuales receptores inmediatos ${ }^{1}$.

Todos esos factores implican, especialmente en el terreno literario, una diferenciación tanto linguística como estética del objeto de estu-

${ }^{1}$ Podemos sintetizar la peculiaridad de la cultura y la literatura gallegas en seis puntos: 1) Sustratos culturales propios (celta y suevo); 2) Situación geografica periférica y marítima; 3) Situación lingǘística compleja y conflictiva (diglosia/ bilingüismo); 4) Circunstancias políticas (Regionalismo, Autonomismo, Nacionalismo); 5) Marginalidad y 6) Oralidad, tradicionalidad y popularismo. 
dio que, en consecuencia, exige una adaptación no tanto de los métodos científicos generales como de los métodos de análisis y de interpretación. El hecho de que exista una literatura muy bien diferenciada, tanto por la lengua en que está escrita como por el contexto geográfico y sociocultural en que es producida, implica la configuración de un método semiótico específico al corpus cultural y literario gallegos; si el método científico general es universal, nada impide que sus resultados sean expresados mediante un discurso crítico que no sólo esté plasmado en lengua gallega, sino que responda a la especificidad estructural, funcional y pragmática del sistema constituido por los textos escritos en esa lengua.

En una circunstancia de valor histórico indudable, la primera Conference on Galician Studies, celebrada en la Universidad de Oxford en 1991, el profesor Tarrío Varela ponía de relieve la necesidad de la renovación metodológica en los estudios de literatura gallega: Nestas condicións, non é de estrañar que a investigación e a crítica que se fixo ata hai moi poucas décadas se levase a cabo, agás raras excepcións, sen metodoloxías axeitadas, sen ningún tipo de sistematización e aplicando, as máis das veces, o puro intuicionismo... (1993b: 85). La creación cultural gallega constituye un sistema peculiar, periférico y marginal, y desde este presupuesto empírico hay que estudiarla. Premisa que se apuntaba en otro texto de carácter fuertemente programático, la Presentación del Anuario de Estudios Literarios Galegos, revista con un notable componente teórico-crítico:

\begin{abstract}
As condicións concretas nas que se desenvolve a literatura galega camo un sistema literario menor, e as repercusións desta situación na producción crítica, forzan a recoñocer a urxencia de determinados estudios que desexamos alentar nas páxinas do Anuario, e que deben pasar por un renovado esforzo de clarificación conceptual e operativo de termos como autor, lector, texto, discurso, canon, identidade, representación, marxinalidade ou nación. Sería desexable que das páxinas do Anuario, coma das outras publicacións periódicas coas que dende agora comparte o espacio público da praxe crítica galega, xurdise unha contribución específica ó estudio dos sistemas literarios menores ou marxinais; e que se potenciase unha historiografía do diálogo, que todos sabemos desigual e conflictivo, entre a literatura galega e os outros sistemas literarios... (González Millán, 1992: 7-8).
\end{abstract}

Todas esas circunstancias específicas de la literatura gallega implican un discurso semiótico específico que empieza a configurarse ya en publicaciones científicas y universitarias como el citado Anuario o el Boletín Galego de Literatura, del Departamento de Filoloxía Galega 
da Universidade de Santiago, en las que se acogen sistemáticamente trabajos de orientación semiótica.

Ya los historiadores de la Literatura Gallega pusieron de manifiesto unos conocimientos teóricos y críticos de gran solidez, avanzando y aplicando desde muy pronto las aportaciones del estructuralismo y de la semiótica más formalista al estudio de nuestra literatura. De 1956 es la Historia de la literatura gallega que, junto a la posterior «Literatura Gallega», fueron escritas en castellano por el profesor Varela Jácome, mentor de los comentarios semiológicos de textos literarios a los que ya nos hemos referido. Pero es el profesor Ricardo Carballo Calero quien redacta una extensa Historia da Literatura Galega Contemporánea (1963), a principios de los años sesenta, que sorprende todavía hoy por su rigor científico y por lo avanzado de sus planteamientos en el análisis de los principales textos poéticos, narrativos y dramáticos de nuestra historia literaria.

En la senda abierta por esos pioneros, la Semiótica ha venido ocupándose, cada vez en mayor medida, de la literatura, el teatro o el cine gallegos al hilo tanto de los géneros como de los textos y autores más importantes. Discípula de Carballo Calero, Araceli Herrero Figueroa (1994) plantea un método de análisis textual semiológico de inspiración netamente genetiana que aplica inteligentemente a la didáctica de la literatura gallega, centrándose particularmente en autores como Luis Pimentel o Âlvaro Cunqueiro.

Si la narrativa gallega moderna y contemporánea encuentra una explicación peculiar en términos de la fantasticidad estudiada por el profesor Antón Risco, de la Universidad Laval, las investigaciones narratológicas sobre la novela y el cuento escritos en lengua gallega ha generado una interesantísima bibliografía. Desde la óptica de la semiótica soviética, en la línea metodológica que va de Bajtín a Lotman y Mignolo, Vilavedra (1993a, 1993b y 1994) realiza el estudio más amplio y ambicioso, interesándose por las estrategias enunciativas y polifónicas explotadas textualmente en la novela gallega. Dado lo inagotable del tema, valgan como botón de muestra las ingentes y exhaustivas investigaciones sobre nuestro mayor novelista, Álvaro Cunqueiro, cuya obra exhibe una originalísima configuración ficcional de naturaleza híbrida, real-fantástica y real-maravillosa (Tarrío, 1989 y 1993a; Morám Fraga, 1990; González Millán, 1991 y 1993; Varela Jácome, 1982 y 1993; Villanueva, 1992b y 1993; Real Pérez, 1994; Rodríguez Vega, 1994). 
La riquísima tradición lírica de la literatura gallega también ha acaparado la atención de los investigadores. Si Anxo Tarrío (1992) expone precisamente los postulados del método semiótico ejemplificando con el poema Deluvei os ollos del poeta Antón Tovar, en esa misma Antología de comentarios de texto, enuncia Arturo Casas (1992) los postulados del método pragmático utilizando un poema de Curros Enríquez, cuya poesía narrativa había sido objeto de otros análisis semióticos (Paz Gago, 1992a). También a la obra poética de Rosalía de Castro se han dedicado abundantes trabajos semiológicos, como puede apreciarse en los tres volúmenes de las Actas del Congreso Internacional de estudios sobre Rosalía de Castro y su tiempo (Santiago de Compostela, 1986).

En lo que se refiere al teatro, existen panoramas metodológicos en gallego en los que se exponen y discuten los principios básicos de la semiótica teatral (Núñez Ramos, 1988; Bobes Naves, 1997; Vieites, 1995,1996 y 1997). Al teatro menor galaico-portugués consagra una importante monografía Nodar Manso (1992), en la que expone sus originales tesis sobre la teatralidad y la espectacularidad de la lírica gallego-portuguesa medieval. Ha merecido especial atención la configuración textual y actancial de las piezas dramáticas más importantes del teatro gallego como Os vellos non deben de namorarse de Castelao, de la que realizó Carballo Calero (1984) un excepcional análisis estructural, toda la obra teatral de Álvaro Cunqueiro (Herrero Figueroa, 1991, 1993 y 1994; Paz Gago, 1993b, 1993c, 1997) o la de Rafael Dieste, profundamente estudiada por Arturo Casas (1994b y 1997).

Tras una primera etapa de tendencia formalista y estructuralista, como correspondía a la época, la Semiótica gallega se abre a planteamientos teóricos más globales, incorporando las aportaciones generales de la Pragmática y de sus principales componentes metodológicos como la Teoría de la ficción, Estéticas y Teorías de la recepción, Fenomenología, Hermenéutica... A principios de la década de los noventa ya está consumado ese proceso metodológico, tal como se manifiesta en la importante ponencia que pronuncia Anxo Tarrío en el Congreso dedicado a la obra de Álvaro Cunqueiro, en 1991. Se refería en esa ocasión el especialista compostelano al paradigma semióticoformalista, surgido de la necesidade de lexitimar os estudios lingüistico-literarios mediante o seu achegamento ás denominadas ciencias da natureza, consagrando la lingüística como modelo científico e incluso como ciencia nai da semiótica ou semioloxía. Tras poner de manifiesto los excesos y aberraciones a los que en ocasiones llevó, Tarrío Varela reconocía que a actividade semiótico-formalista foi beneficio- 
sa para armar ó estudioso da literatura con renovados instrumentos de análise, con nova terminoloxía e novos conceptos y ponía de manifiesto que, de todos modos, unha desviación dos obxectivos primordiais e dos fins desas análises desembocou, en moitos casos, en facer do instrumento fin en si mesmo e da literatura unha simple pista de probas na que observar o comportamento diferenciado que a linguaxe humana, e aínda a actividade semiótica humana en xeral, amosaba no feito literario. Feito que, xa que logo, pasou en moitos casos a poñerse ó mesmo nivel, como obxecto de estudio e de observación, que calquera outra manifestación lingüística, sen ter en conta as dimensións ficticia e estética que o definen (1993a: 152-153). Aun valorando en su justa medida esta reflexión, las duras críticas que se dedican en este texto al mantenimiento epigónico del modelo formalistaestructural pueden parecer, sin embargo, inútiles en un momento en que tal paradigma ya está definitivamente superado.

\section{LA CREACIÓN DE LA ASOCIACIÓN GALEGA DE SEMIÓTICA: EL CONGRESO SEMIÓTICA Y MODERNIDAD (1992)}

En el año 1990 se produce en la Comunidad Autónoma de Galicia la llamada segregación, en virtud de la cual aparecen en el panorama gallego dos nuevas y jóvenes Universidades, la de La Coruña y la de Vigo, con los Campus asociados de Pontevedra, Ourense, Ferrol y Lugo, en los que pronto surgen núcleos de investigación semiológica estrechamente vinculados a Santiago y a Oviedo.

A propuesta de los profesores Fernando Cabo y José María Paz Gago, la Asociación Española de Semiótica encarga, en 1992, la organización de su V Congreso Internacional a la Universidad de La Coruña. Este importante Congreso, que reúne en la ciudad gallega a más de quinientos investigadores de España y de otros países europeos y americanos, con una importante participación gallega, significa un nuevo detonante con resultados científicos tangibles, la publicación de dos volúmenes de Actas bajo el título genérico de Semiótica y Modernidad (1994) y la creación de una Asociación Gallega de Semiótica.

Como conjunto de métodos que permiten analizar e interpretar todos los acontecimientos sociales y cotidianos, políticos e históricos, cultu- 
rales y artísticos en tanto que fenómenos comunicativos, se revelaba la Semiótica como el instrumento científico idóneo para la reflexión sobre el origen y el vaticinado fin de la Modernidad, históricamente enmarcada en los cinco siglos que van de 1492 a 1992. Medio centenar de especialistas en las diversas ramas de la Semiótica -teórica, literaria, visual, cultural, etc.- - se reunían en la ciudad gallega para tratar de descodificar los signos de los viejos y de los nuevos tiempos, de desentrañar la significación de esos dos momentos claves de la Modernidad: su inauguración, en aquella fecha memorable del descubrimiento de un Nuevo Mundo, y su presunta clausura con el advenimiento de lo que ha dado en llamarse Postmodernidad.

Junto a las grandes personalidades de la ciencia semiótica como Eco o Lotman, cuyos textos incluyen estas Actas, el profesor Darío Villanueva (1994: 35-58), de la Universidad de Santiago de Compostela, reclamaba en la Ponencia Inaugural una semiótica de la comunicación, que considere la totalidad de la semiosis desde una perspectiva pragmática, para analizar procesos culturales y sociales tan complejos como los que el Congreso abordaba. Su propuesta se centraba, pues, en una Semiótica Pragmática, orientación de última generación que se revelaba indispensable para poder dar una visión actual de aquel encuentro/choque de dos mundos que significó el Descubrimiento de América.

La figura más destacada de la semiótica gallega situaba con precisión el nuevo paradigma teórico al reivindicar la Pragmática, que se ocupa, como Morris formuló, de la relación de los signos con sus intérpretes, frente a las otras dos partes de la Semiótica más formalizables desde el punto de vista lingüístico que son la Sintáctica y la Semántica (1994: 38), en la línea doctrinal que va de Peirce a Parret y Eco, reclamaba el enfoque pragmático como dimensión esencial de la totalidad de la semiosis, que sólo puede ser comprendida desde ese punto de vista global. Incorporando la hermenéutica fenomenológica, tan ligada a su pensamiento semiótico, Villanueva identificaba signos con realidades, exigiendo de ese modo la dimensión pragmática en su consideración. Tal planteamiento metodológico le llevaba a una conclusión de no poca trascendencia: Con ello pienso, además, que no nos limitamos tan sólo a completar debidamente el paradigma semiótico, sino que cumplimos con un imperativo ético (1994: 39).

El segundo volumen de estas Actas, trascendentales para la Semiótica española y gallega, recoge una amplia reflexión semiótica sobre la Postmodernidad, nueva etapa de la historia de la civilización 
occidental o simple moda cultural, que se manifiesta antes que nada en la reflexión estética tanto en el dominio de las artes plásticas como en el de la literatura. Entre las importantes aportaciones sobre novela y poesía actual, prensa, cine y televisión que el texto contiene, se encuentra no sólo la afirmación de la existencia de una novela postmodernista en España, amplia, original y bien enraizada en nuestra tradición literaria, sino también de una poesía postmoderna.

Mediante el profundo análisis teórico-crítico de textos y autores llevado a cabo por los congresistas quedaba demostrado el vigor de la novela postmoderna de las últimas generaciones, con antecedentes tan relevantes como el escritor gallego Valle Inclán y representantes en la literatura de Galicia como Cunqueiro, sin duda el escritor gallego mejor integrado en el contexto postmodernista internacional. Esta revalorización del fenómeno literario postmoderno en nuestro país se hace aquí extensiva al teatro y a la poesía contemporáneos. Dos poetas estrechamente vinculados a Galicia enmarcarían esta tendencia: Vallejo, quien desde una revista editada precisamente en la ciudad gallega, Alfar, desencadenó todo un programa de crítica de la cultura occidental moderna mediante la transgresión y la subversión de su propio discurso, y Valente, escritor orensano de profundo significado.

La organización de este $V$ Congreso Internacional de la Asociación Española de Semiótica sirvió para que un nutrido grupo de investigadores gallegos -Darío Villanueva, Fernando Cabo, Araceli Herrero Figueroa, Dolores Vilavedra, Xosé Anxo Fernández Roca, Carlos Gómez Blanco, Xosé María Dobarro, Manuel Cousillas, etc.- pensara en la posibilidad de crear una Asociación Galega de Semiótica, que quedaría constituida en 1993.

En efecto, con ocasión de un Seminario científico internacional ese mismo año, en el que participaron entre otros los profesores Carmen Bobes Naves y Alberto Álvarez Sanagustín, se aprobó el Acta de Constitución, en presencia de Jorge Lozano, Director de la Academia de Historia, Arte y Arqueología de España en Roma y entonces representante de nuestro país en el Bureau de la IASS. Al mismo tiempo, se formó una Junta Directiva Gestora a la que se confió la redacción de los Estatutos.

En abril de 1994 se celebraba el primer Simposio de la Asociación, dedicado a las nuevas perspectivas semióticas en los estudios de Feminismo y de Literatura y Cine. Contamos con la participación del profesor Thomas A. Sebeok, Redactor-Jefe de Semiótica, Sultana 
Wahnon, Vicepresidenta de la Asociación Española de Semiótica, Iris M. Zavala, de la Universidad de Utrecht, y Jenaro Talens, de las Universidades de Valencia y Minnesota; representantes de las Comunidades Autónomas de Cataluña, Andalucía, Canarias, La Rioja y País Vasco y participantes de las tres Universidades -con sus siete Campus - y de buena parte de los Institutos de Bachillerato gallegos. Se trató de un Simposio modesto pero denso que, dirigido por el profesor Carlos J. Gómez Blanco, Vicepresidente de la AGAS, reunió a un centenar de especialistas, en su mayoría procedentes de Galicia, para abordar los dos temas generales planteados: «Literatura y cine» y «Nuevas perspectivas semióticas».

Editado por Carlos J. Gómez Blanco, este volumen de Actas recogió los trabajos de este primer encuentro, libro que significó la primera publicación colectiva de la Asociación, breve en extensión pero trascendental por el valor de su contenido científico y porque anunciaba un futuro prometedor.

Un Coloquio sobre Narrativa Española Contemporánea en 1996, y el Simposio Internacional Cen Anos de Cine. Historia, Teoría e Análise do Texto fílmico, en 1997, constituyeron otras dos importantes reuniones científicas en las que intervinieron especialistas de renombre internacional como Ricardo Senabre, Gonzalo Navajas, Samuel Amel o Ken Benson; Jenaro Talens, Román Gubern, José Romera Castillo, Santos Zunzunegui, Jorge Urrutia o François Jost, Nicolás Rosa y Lucrecia Escudero, presidente y vicepresidenta, respectivamente, de la Federación Latinoamericana de Semiótica.

Todas estas actividades académicas contribuyeron decisivamente a consolidar el trabajo de docencia e investigación desarrollado en nuestra Comunidad Autónoma en los campos preferentes de la Semiótica literaria y visual. Más de dos mil personas entre profesores de Universidad y de Enseñanza Secundaria, investigadores y alumnos universitarios de Segundo y Tercer Ciclo han participado en esta intensa actividad científica, que hace de la Asociación Galega de Semiótica una entidad activa y productiva.

Se hacían así realidad las expectativas expresadas por Carmen Bobes Naves, elegida Presidenta de Honor de AGAS, cuando trazaba el panorama de la semiótica española: También reseñamos la existencia en diversas Comunidades, y siempre centradas en las universidades, de asociaciones de semiótica, la andaluza (AAS), cuyo órgano de expresión es Discurso. Revista Internacional de Estudios Semióticos; la 
Asociación de Estudios Semióticos de Barcelona (AESBA), que edita la revista Estudios Semióticos; la vasca, que organiza algunos simposios casi siempre con la vista puesta en autores franceses; y la gallega, que está a punto de formarse, y sobre cuya actividad y orientación veremos en el futuro, cuando se manifieste en obras (1994: 14-15).

En 1997 se celebró en la Universidad de Vigo el II Simposio de AGAS, dedicado al relato corto. Bajo el título general de Asedios ó conto, esta nueva reunión, organizada por las profesoras Carmen Becerra, María Jesús Fariña y Beatriz Suárez Briones, ofreció un panorama pluridisciplinar sobre la narrativa breve de ficción.

\section{PRINCIPALES GRUPOS DE INVESTIGACIÓN EN LA ACTUALIDAD}

4.1. El Grupo de la Universidad de Santiago de Compostela, dirigido por Darío Villanueva, encuentra su especificidad en un componente fuertemente fenomenológico y hermenéutico que lo vincula a la Semiótica peirceana la cual, como el propio Villanueva recuerda, se fundamenta en lo que Peirce denominó su faneroscopia o fenomenografía, término que designa en su particular sistema la disciplina que se limita a describir las apariencias inmediatas con exactitud máxima (1991a: 42). Efectivamente, para evitar excesivas connotaciones kantianas y husserlianas, Peirce opta por denominar Faneroscopia a su Fenomenología, la ciencia descriptiva de las tres en que divide la Filosofía. De todos modos, Peirce está muy cerca de Husserl cuando considera el faneron o fenómeno como una presencia en la mente, consistiendo el trabajo fenomenológico en abrir los ojos de la mente y observar sus caracteres (cf. Castañares, 1987: 133).

De este modo, esta interesante Escuela dentro de la Semiótica gallega se constituye en una fenomenología de la lectura o, mejor, en una crítica fenomenológica de la recepción literaria y visual, de orientación fuertemente pragmática, que su director no deja de entroncar también con la Semiótica de Carmen Bobes (1991a: 42). Aplicada tanto a los textos literarios como al cine y al teatro, entre los representantes de este activo grupo, que ha producido una abundante biblografía de primera línea, se encuentran F. Cabo, A. Casas, M. Iglesias o A. Abuín. 
Entre las principales líneas de investigación hay que incluir la Pragmática y la Teoría de la recepción, aplicada tanto al teatro como al texto lírico o narrativo, con especial atención a la teoría de la enunciación lírica. La muestra más valiosa de las contribuciones de los componentes del Grupo de Santiago es el volumen colectivo Avances en Teoría de la literatura, publicado en 1994 por la Universidade de Santiago de Compostela, bajo la dirección de Darío Villanueva, en el que se contiene una interesante puesta al día de los métodos más innovadores de la dos últimas décadas del siglo: Pragmática, Estética de la Recepción, Teoría Empírica de la Literatura y Teoría de los Polisistemas.

Si Ángel Abuín (1997) investiga la mediación narrativa en la comunicación teatral, Fernando Cabo (1992) publica un estudio definitivo sobre el concepto pragmático de género aplicado a la literatura picaresca, considerada en su dimensión enunciativa, trabajo que ha tenido una honda repercusión en los estudios áureos y de Teoría literaria. Caso especial en el Grupo es Arturo Casas (1997), que ha desarrollado una solidísima investigación sobre la Teoría estética, teatral y literaria de uno de los escritores gallegos más importantes del siglo, Rafael Dieste.

La Semiótica Teórica también ha encontrado atención en las universidades gallegas, especialmente en la de Santiago: mientras que Rivas Monroy (1994 y 1996) se ha convertido en una destacada especialista en la obra de Peirce, que ha puesto en conexión con Frege, Agís Villaverde (1993 y 1995), por su parte, estudia la propuesta teóricohermenéutica de Ricoeur. En el contexto fenomenológico compostelano, Agís Villaverde (1994 y 1997) analiza concienzudamente el discurso hermenéutico del autor de La metáfora viva poniéndolo también en relación con las propuestas semiótico-discursivas de Gadamer o Derrida.

4.2. En la Universidad de La Coruña trabaja un activo grupo que, directamente vinculado a la semiótica peirceana y a la obra de Bobes Naves, despliega también una amplia actividad científica que se refleja en congresos, seminarios y publicaciones.

Alumno en sus estudios de Doctorado de la profesora ovetense, José Ángel Fernández Roca (1996, 1997, 1998a, 1998b) lleva a cabo análisis semiológicos de los textos, narrativos o dramáticos, de grandes escritores gallegos en castellano como Valle-Inclán o Torrente Ballester; en esa misma línea bobesiana de explotación de los mode- 
los de análisis semióticos en el estudio de los diferentes géneros literarios se inscribe buena parte del trabajo en semiótica literaria de quien esto escribe, aplicada a la novela (Paz Gago, 1995; cf. Fernández Roca $1998 c)$, a la poesía $(1986,1998)$ o al teatro, preferentemente escrito y representado en gallego.

La semiótica teatral ha contado con una atención preferente por parte de investigadores como F. Nodar Manso, F. López Criado, C. Blanco Dávila o A. Rodríguez López-Vázquez. Autor de una extensa obra de investigación, Nodar Manso aborda la génesis de la representación teatral, tanto en la Antiguiedad griega como en el medioevo gallego, dedicando originales monografías a ambos períodos (1992, 1996). López Criado (1994, 1996) y, en su senda, Blanco Dávila (1996) analizan los procesos imaginativos y enunciativos de un teatro vanguardista excepcional, el de Ramón Gómez de la Serna. También trabaja sobre teatro de vanguardia el profesor Rodríguez LópezVázquez (1996b), conocido por sus revolucionarias ediciones críticas, realizadas con criterios netamente semióticos, del teatro áureo (1990), al que pone en relación con el teatro contemporáneo (1992b y 1992c).

En el seno del Grupo coruñés han adquirido especial relevancia las investigaciones en Semiótica visual, especialmente en Semiótica fímica como es buena prueba el volumen sobre las relaciones entre Literatura y Cine, desde una perspectiva semiótica, editado por Carlos Gómez Blanco (1997) para quien tal relación se basa en el hecho de que la semiosis es muy distinta, pues estamos hablando de medios de comunicación y creación estética cuya significación se produce a través de signos muy distintos (1997: 13). En este ámbito se inscribe la teoría del cinerrador, instancia de enunciación específicamente cinematográfica (Paz Gago, 1997), en la que profundizan S. Caaveiro (1997) o M. Gómez Padilla (1997) al analizar las transposiciones cinematográficas de dos novelistas gallegos, Wenceslao Fernández Flórez y Camilo José Cela. Las intensas relaciones entre novela naturalista y cine son abordadas por A. Rodríguez López-Vázquez (1997a), atento a la circulación de los grandes mitos a través de los soportes literarios, teatrales y cinematográficos $(1988,1992 b)$. Esta línea de investigación culminó en el Simposio Internacional Cien Años de Cine. Historia, Teoría y Análisis del texto fílmico, en 1997 (Castro de Paz y Paz Gago eds., en prensa).

Por otra parte, en el núcleo semiológico de La Coruña se ha propiciado una apertura hacia nuevos campos de investigación como el fol- 
clore y la literatura oral (Cousillas, 1996, 1997 y 1998b), la música y la pintura (Nodar Manso, 1997 y 1998) o las nuevas tecnologías de la comunicación. En efecto, Manuel Cousillas (1998) ha realizado un intenso estudio de las tradiciones orales de la Costa da Morte en clave semiótica y pragmática, que culmina en su monografía Literatura popular en la Costa de la Muerte. Enfoque semiótico.

4.3. La investigación semiótica en la Universidad de Vigo compendia y sintetiza las bases teóricas aquí apuntadas: si la profesora Carmen Becerra, actual vicepresidenta de la Asociación Galega de Semiótica, se vincula a la Fenomenología compostelana, el profesor Jesús $\mathbf{G}$. Maestro es otro de los discípulos destacados de la profesora Bobes Naves.

Los campos de investigación más cultivados en la Universidad viguesa son la semiología teatral (González Maestro, ed.; 1996), la narrativa (Becerra Suárez, ed.; 1998) o la crítica feminista (Fariña Busto y Suárez Briones, 1994; Fariña Busto, 1996 y Suárez Briones, 1996). En estos ámbitos destaca la organización de Congresos sobre Teoría teatral, profundamente marcados por los planteamientos teatrales semióticos de Tadeusz Kowzan (1996) y de Carmen Bobes (1996), o del II Simposio de la Asociación Galega de Semiótica, consagrado a la narrativa ficcional breve, con la participación de destacados semiólogos como José Romera Castillo y José María Pozuelo.

También en el seno de este grupo conviven perspectivas diferentes: desde el enfoque mitocrítico y hermenéutico, vinculado directamente a autores como Lévi-Strauss o Ricoeur, de C. Becerra (1997), a la explotación de los modelos formales y pragmáticos de la Semiótica literaria y teatral, particularmente centrados en las operaciones pragmáticas de transducción tanto en la poesía lírica como en el texto dramático (González Maestro, 1994 y 1996).

En el terreno de la semiótica fílmica y televisiva se centra la actividad investigadora del profesor José Luis Castro de Paz, de la Universidad de Vigo en el Campus de Ourense, autor de estudios definitivos sobre aspectos formales y significativos de las realizaciones televisivas de Hitchcock (1996 y 1997b) y especialista en análisis del texto cinematográfico (1995a) o en metodologías de análisis aplicadas a la historia del cine tanto norteamericano (1997b) como español y gallego (1995b, Castro de Paz, ed., 1996; Castro de Paz y Paz Gago, eds., e.p.). 


\section{EPílogo}

Este panorama de la Semiótica gallega que acabamos de trazar es necesariamente limitado, pues resulta imposible citar a todos los autores y dar cuenta de todas las investigaciones, máxime cuando algunas de ellas todavía no han sido publicadas. La exposición de los distintos grupos que trabajan hoy en Galicia, en los diferentes Campus y Universidades, no debe dar la falsa impresión de equipos impermeables, de compartimentos estancos y de un aislamiento científico que sería lamentable. La realidad es que el buen entendimiento entre los diferentes grupos permite unas relaciones humanas y científicas inmejorables, facilitando un intercambio incesante propiciado por la Asociación Galega de Semiótica, que reúne a investigadores venidos de todos los lugares y horizontes. La intensa actividad semiótica que hoy se desarrolla en Galicia tendrá una importante culminación en el IV Congreso de la Federación Latinoamericana de Semiótica, a finales del año 1999.

Dado que el pueblo gallego ha sido siempre un pueblo de emigrantes, de transterrados, no podemos poner punto final a este trabajo a manera de informe de urgencia sobre el estado de las investigaciones semióticas en Galicia sin citar a los investigadores gallegos del exterior como Juan Ángel Magariños de Morentín de la Universidad de La Plata (Argentina), uno de los representantes más destacados en el campo de la Semiótica de enunciados, Carlos Peregrín Otero, estrecho colaborador de Noam Chomsky, o Antón Risco quien, tras largos años de trabajo en Universidades norteamericanas y canadienses, regresó a su querida Galicia donde fallecía recientemente. Dedicamos estas páginas a la entrañable memoria de quien ejerció su último puesto universitario como profesor visitante de la Universidade da Coruña.

\section{Bibliografía}

ABỨN GoNZÁleZ, A. (1993). «Drama, estilo, narración. Notas sobre las acotaciones escénicas». Hispanística 20/11, 191-203.

- (1996). «La mano invisible: reflexión teórica de los directores de escena en la postguerra». En Problemata Theatralia. El signo teatral: texto 


\section{La Semiótica en Galicia: la Asociación Gallega de Semiótica}

y representación, González Maestro, J. (ed.), 1-12. Vigo: Universidade de Vigo.

- (1997). El narrador en el teatro. Santiago: Universidade de Santiago de Compostela.

Agís Villaverde, M. (1993). El discurso filosófico. Análisis desde la obra de Paul Ricoeur. Santiago: Universidade de Santiago. Tesis inédita.

- (1994). «Testo filosofico e interpretazione: Paul Ricoeur e HansGeorg Gadamer». En Il testo filosofico: Ermeneutica: teoria e pratica, Costa, F. (ed.). Palermo: l'Epos.

- (1995). Del símbolo a la metáfora: Introducción a la filosofía hermenéutica de Paul Ricoeur. Santiago: Universidade de Santiago de Compostela.

- (1997). «Metáfora y filosofía. En torno al debate Paul Ricoeur-Jacques Derrida». En Horizontes del relato. Lecturas y conversaciones con $P$. Ricoeur, Aranzueque, G. (ed.). Madrid: Universidad Autónoma de Madrid.

Agís VillaVerde, M. (ed.) (1998). Horizontes de la Hermenéutica. Santiago: Universidade de Santiago.

Álvarez Sanagustín, A. (1981). Semiología y Narración. Oviedo: Universidad de Oviedo.

- (1992). «Hétérogénéité énonciative et thêâtralité». En Signs of Humanity/L'homme et ses signes, Deledalle, G., Balat, M. y DeledalleRhodes, J. (eds.), vol. 2, 1.155-1.161. Berlín: Walter de Gruyter.

BECERRA SUÁREZ, C. (1996). «El mito y su tratamiento teatral: Ulises y Tobías». En Problemata Theatralia. El signo teatral: texto y representación. González Maestro, J. (ed.), 29-41. Vigo: Universidade de Vigo.

- (1997a). Mito y literatura (Estudio comparado de Don Juan). Vigo: Universidade de Vigo.

- (1997b). «El infierno de don Juan: la versión de Gonzalo Suárez». En Literatura y Cine: Perspectivas Semióticas, Gómez Blanco, C. (ed.), 19-28. A Coruña: Universidade da Coruña.

Becerra SuÁrez, C. (ed.) (1998). Asedios ó conto. Actas del II Simposio de la Asociación Galega de Semiótica. Vigo: Universidade de Vigo. En prensa.

Blanco, C. (1992). «O método estructural: Laberinto de Xosé Luis Méndez Ferrín». En Comentarios de textos contemporáneos. Rodríguez $\mathrm{Fer}, \mathrm{Cl}$. (ed.), 45-68. Vigo: Xerais.

Blanco DÁvila, C. (1994). «Narciso como modelo erótico en la obra de Salvador Dalí». En Semiótica y Modernidad. Investigaciones Semióticas $V$. Actas del $V$ Congreso Internacional de la Asociación Española de Semiótica, Paz Gago, J. M. et al. (eds.), vol. 2, 341-350. A Coruña: Universidade da Coruña.

- (1996). «La dimensión deíctica en la doble enunciación del discurso teatral de Ramón Gómez de la Serna». En Problemata Theatralia. El signo teatral: texto y representación, González Maestro, J. (ed.), 4257. Vigo: Universidade de Vigo. 
Bobes Naves, M. C. (1973). La semiótica como teoría lingüística. Madrid: Gredos.

- (1975). Gramática de Cántico. Madrid: Cupsa Editorial-Universidad de Oviedo.

- (1987). Semiología de la obra dramática. Madrid: Taurus.

- (1994). «La semiología en España». En Retos actuales de la Teoría Literaria. Paraíso, I. (ed.), 11-30. Valladolid: Universidad de Valladolid.

- (1996). «El diálogo en el teatro actual». En Problemata Theatralia. El signo teatral: texto y representación, González Maestro, J. (ed.), 5880. Vigo: Universidade de Vigo.

- (1997). «O diálogo primario da representación dramática». Revista Galega de Teatro 15, 64-69.

Bobes Naves, M. C. (ed.) (1974). Crítica Semiológica. Santiago: Universidad de Santiago de Compostela. (2. ${ }^{a}$ ed.) Oviedo: Universidad de Oviedo, 1977.

CAAVEIRo BARcÍA, S. (1997). «El bosque animado: versión literaria, versión fîmica». En Literatura y Cine: Perspectivas Semióticas, Gómez Blanco, C. (ed.), 29-36. A Coruña: Universidade da Coruña.

CaAveiro Barcía, S. y Gómez Padilla, M. (1994). «Análisis de las telenovelas». En Semiótica y Modernidad. Investigaciones Semióticas V. Actas del $V$ Congreso Internacional de la Asociación Española de Semiótica. Paz Gago, J. M. (ed.), vol. 2. A Coruña: Universidade da Coruña.

CABO, F. (1990). «La enunciación lírica y la actio retórica». En Investigaciones Semióticas III. Retórica y Lenguajes, vol. 1, 215-224. Madrid: UNED.

- (1992). El concepto de género y la literatura picaresca. Santiago: Universidade de Santiago de Compostela.

- (1994). «Sobre la Pragmática de la Teoría de la ficción literaria». En Avances en Teoría de la literatura, Villanueva, D. (ed.), 187-228. Santiago: Universidad de Santiago de Compostela.

- (1995). «Fenomenología y enunciación lírica: Ortega, Ferraté, Gil de Biedma». Tropelías 5/6, 67-82.

- (1998). «Entre Narciso y Filomela: enunciación y lenguaje poético». En Teoría del poema. La enunciación lírica, Cabo, F. y Gullón, G. (eds.). Amsterdam y Atlanta: Rodopi.

CABo, F. y Gullón, G. (eds.) (1998). Teoría del poema. La enunciación lírica. Amsterdam y Atlanta: Rodopi.

Carballo Calero, R. (1963). Historia da Literatura Galega Contemporánea. Vigo: Galaxia. (3. ${ }^{\mathrm{a}}$ ed. 1981).

- (1979). Libros e autores galegos, vol. 1. A Coruña: Fundación Barrié de la Maza.

- (1982). Libros e autores galegos, vol. 2. A Coruña: Fundación Barrié de la Maza.

- (1984). Letras galegas. A Coruña: Asociación Galega da Lingua.

Casas, A. (1992). «Análise pragmática de textos líricos. Aplicacións sobre un poema de Curros Enríquez». En Comentarios de textos contemporáneos, Rodríguez Fer, Cl. (ed.), 141-170. Vigo: Xerais. 
- (1994a). «Pragmática y poesía». Avances en Teoría de la literatura. Villanueva, D. (ed.), 229-308. Santiago: Universidad de Santiago de Compostela.

- (1994b). Rafael Dieste e a súa obra literaria en galego. Vigo: Galaxia.

- (1997). La teoría estética, teatral y literaria de Rafael Dieste. Santiago: Universidade de Santiago e Deputación de A Coruña.

CASTRo de PAZ, J. L. (1995a). «Los ojos atrapados en el lienzo (Vértigo de A. H.)». En El análisis cinematográfico. Modelos teóricos, metodologías, ejercicios de análisis, González Requena, J. (ed.), 253-269. Madrid: Universidad Complutense.

- (1995b). La Coruña y el cine. 100 años de historia. A Coruña: Vía Láctea.

- (1996). El mundo televisivo de Alfred Hitchcock (los años cincuenta, la crisis de Hollywood y la Televisión). Santiago de Compostela: Universidade de Santiago, Tesis inédita.

- (1997a). La forma televisiva de Alfred Hitchcock. Valencia: Eutopías.

- (1997b). A crise da transparencia clásica. Enturbamentos e desaxustes no cine de Hollywood, 1946-1960. A Coruña: Vía Láctea.

CAstro de PAZ, J. L. (ed.) (1996). Historia do cine en Galicia. A Coruña: Vía Láctea.

Castro de Paz, J. L. y Paz Gago, J. M. (eds.) (e.p.). Cen anos de Cine. Historia, Teoría e Análise do texto filmico. Madrid: Visor y Universidade da Coruña.

Cousillas Rodríguez, M. (1996). «Naturaleza ficcional de las leyendas folclóricas». En Mundos de ficción, Actas del VI Congreso Internacional de la Asociación Española de Semiótica, Pozuelo, J. M. y Vicente, F. (eds.), vol. 1, 527-534. Murcia: Universidad de Murcia.

- (1997). «Rasgos semióticos de los espíritus malignos en Corme: duendes, lavanderas y el demonio». En Literatura y Cine: Perspectivas Semióticas. Gómez Blanco, C. (ed.), 187-200. A Coruña: Universidade da Coruña.

- (1998a). Literatura popular en la Costa de la Muerte. Enfoque semiótico. Ponteceso: Excmo. Concello de Ponteceso.

- (1998b). «Mitos celtas en la Costa de la Muerte». En Actas del VII Congreso Internacional de la Asociación Española de Semiótica. Blesa, T. (ed.). Zaragoza: Universidad de Zaragoza, en prensa.

- (1998c). «Naturaleza y folclore en la Costa de la Muerte». En Actas del VI Congreso Internacional de International Association for Semiotic Studies. Guadalajara (México), en prensa.

FARIÑA BUSTO, M. J. y SUÁREZ BRIONES, B. (1994). «La crítica literaria feminista: una apuesta por la modernidad». En Semiótica y Modernidad. Investigaciones Semióticas $V$. Actas del $V$ Congreso Internacional de la Asociación Española de Semiótica, Paz Gago, J. M. et al. (eds), vol. 1, 321-332. A Coruña: Universidade da Coruña. 
FARIÑa BUSTO, M. J. (1996). «Una cuestión de géneros. Inversión y dramatización del Quijote en Le voyage sans fin de Monique Wittig». En Problemata Theatralia. El signo teatral: texto y representación. González Maestro, J. (ed.), 91-103. Vigo: Universidade de Vigo.

FERnÁNDEZ RoCA, X. A. (1996). «Lectura semiótica de Lope de Aguirre de Torrente Ballester desde las acotaciones». En Mundos de ficción, Actas del VI Congreso Internacional de la Asociación Española de Semiótica, Pozuelo, J. M. y Vicente, F. (eds.), vol. 1, 637-643. Murcia: Universidad de Murcia.

- (1997). «Las acotaciones del esperpento: de lo verbal a lo visual». En Literatura y Cine: Perspectivas Semióticas, Gómez Blanco, C. (ed.), 201-211. A Coruña: Universidade da Coruña.

- (1998a). «Mito e ironía en El retorno de Ulises de Torrente Ballester». En Actas del VII Congreso Internacional de la Asociación Española de Semiótica, Blesa, T. (ed.), Zaragoza: Universidad de Zaragoza, en prensa.

- (1998b). «Lo somático y lo cultural en Luces de Bohemia». En Actas del VI Congreso Internacional de International Association for Semiotic Studies. Guadalajara (México), en prensa.

- (1998c). «J. M. Paz Gago, Semiótica del Quijote. Teoría y práctica de la ficción narrativa» (Reseña). Romanistisches Jahrbuch, en prensa.

GaSPAR PORRAS, S. (1994). «La inocencia perdida de Italo Calvino. Estrategias narrativas en El caballero inexistente». En Semiótica y Modernidad. Investigaciones Semióticas $V$. Actas del $V$ Congreso Internacional de la Asociación Española de Semiótica, Paz Gago, J. M. et al. (eds.), vol. 2, 161-168. A Coruña: Universidade da Coruña.

- (1997). «Baixo o signo de Cagney. Referentes cinematográficos na narrativa negra galega». En Literatura y Cine: Perspectivas Semióticas, Gómez Blanco, C. (ed.), 47-59. A Coruña: Universidade da Coruña.

Gómez Blanco, J. C. (ed.) (1997). Literatura y Cine: Perspectivas Semióticas. Actas del I Simposio de la Asociación Galega de Semiótica. A Coruña: Universidade da Coruña.

Gómez PADILLA, M. (1997). «El espacio en el café de Doña Rosa: el cinerrador». En Literatura y Cine: Perspectivas Semióticas. Gómez Blanco, C. (ed.), 67-72. A Coruña: Universidade da Coruña.

GonzÁlez MAestro, J. (ed.) (1996). Problemata Theatralia. El signo teatral: texto y representación. Vigo: Universidade de Vigo.

GonZÁleZ MAESTRO, J. (1990). «Pragmática de la lírica: Teoría de las instancias poéticas (el sujeto interior)». En Investigaciones Semióticas $I V$, vol. 1, 149-160. Madrid: Visor.

- (1994). La expresión dialógica en el discurso lírico. La poesía de Miguel de Unamuno. Pragmática y transducción. Kassel: Reichenberger.

- (1996). «Lingüística y poética de la transducción teatral». En Problemata Theatralia. El signo teatral: texto y representación, González Maestro, J. (ed.), 175-211. Vigo: Universidade de Vigo. 
GonZÁleZ Millán, X. (1991). Álvaro Cunqueiro: os artificios da fabulación.

Vigo: Galaxia.

- (1992). «Presentación». Anuario de Estudios Literarios Galegos 1. Vigo: Editorial Galaxia e Xunta de Galicia.

- (1993). «A poética do discurso narrativo na novelística de Álvaro Cunqueiro». En Congreso Álvaro Cunqueiro, 303-318. Santiago de Compostela: Xunta de Galicia.

Herrero FigueroA, A. (1985). «A Crítica literaria na Galiza». Agalia 1. En 1994, 299-305.

- (1991). «Teatro mítico: Verona e Elsinor. Unha leitura palimpsestuosa». En Simposio Álvaro Cunqueiro. Santiago de Compostela: Associaçom Galega da Lingua. En 1994, 157-176.

- (1992a). «Didáctica do texto lírico. A producción do texto e a reconsideración do emisor». En II Congreso Internacional de Didáctica da Lingua e da Literatura. Las Palmas: Universidad de las Palmas. En 1994, 139-155.

- (1993). «O Teatro elisabethiano de Cunqueiro como metadiscurso teatral. A personaxe dramática». En Congresso Álvaro Cunqueiro. Actas. Herrero Figueroa, A. et al. (eds.). Lugo: Diputación Provincial de Lugo e Associaçom Galega da Lingua. En 1994, 177-190.

- (1994). Sobre Luis Pimentel, Álvaro Cunqueiro e Carballo Calero. Apontamentos de Filoloxía, Crítica e Didáctica da Literatura. A Coruña: O Castro.

KowzAN, T. (1996). «El texto y la representación teatrales. Teatro y signo». En Problemata Theatralia. El signo teatral: texto y representación, González Maestro, J. (ed.), 131-142. Vigo: Universidade de Vigo.

LOPEZ CRIADO, F. (1994). «El teatro de lo imposible y la imposibilidad del teatro innovador de Ramón Gómez de la Serna». En Semiótica y Modernidad. Investigaciones Semióticas V. Actas del V Congreso Internacional de la Asociación Española de Semiótica, Paz Gago, J. M. et al. (eds.), vol. 2, 197-210. A Coruña: Universidade da Coruña.

- (1996). «La ausencia, el silencio y el texto imaginario en el teatro de Ramón Gómez de la Serna». En Problemata Theatralia. El signo teatral: texto y representación, González Maestro, J. (ed.), 155-174. Vigo: Universidade de Vigo.

Morám Fraga, C. C. (1990). O mundo narrativo de Álvaro Cunqueiro. A Coruña: AGAL.

NoDAR MANSo, F. (1992). Teatro menor galaico-portugués. Kassel: Reichenberger.

- (1994). Aproximación al texto del corpus literario universal. Kassel: Reichenberger.

- (1996). «La poesía mélica y el teatro litúrgico coral». En Problemata Theatralia. El signo teatral: texto y representación, González Maestro, J. (ed.), 212-224. Vigo: Universidade de Vigo. 
- (1997). «Pies musicales griegos y modelo de mundo demiúrgico». En Literatura y Cine: Perspectivas Semióticas, Gómez Blanco, C. (ed.), 259-268. A Coruña: Universidade da Coruña.

Núñez Ramos, R. (1988). Semiótica do texto teatral. A Coruña: Cadernos da Escola Dramática Galega 71.

Paz Gago, J. M. (1992a). «Métrica e Narración en A Virxe do Cristal de Manuel Curros Enríquez». Boletín Galego de Literatura 7, 53-59.

- (1992b). «In Defence of Cobi». Catalonia 27, 39-41.

- (1993a). La estilística. Madrid: Síntesis.

- (1993b). «Os proxectos teatrais de Cunqueiro: as pezas curtas». En Congreso Internacional Álvaro Cunqueiro. Santiago de Compostela: Xunta de Galicia. (Ed. esp. Art Teatral 10, 74-78. 1998.)

- (1993c). «Dramaturxia Cunqueirana: Análise de O Incerto Señor Don Hamlet». En Congresso Álvaro Cunqueiro. Actas, Herrero Figueroa, A. et al. (eds.), 163-171. Lugo: Diputación Provincial de Lugo e Associación Galega da Lingua.

- (1995a). Semiótica del Quijote. Teoría y práctica de la ficción narrativa. Amsterdam y Atlanta: Rodopi.

- (1995b). «La finzione come simulazione». Cruzeiro Semiótico 21, 95 105.

- (1997). «Énonciation et reception au cinéma: Le cinémateur». Visual Semiotics. Special Issue. Timisora: Université de Timisora.

- (1998a). La recepción del poema. Pragmática del texto lírico. Kassel: Reichenberger.

Paz Gago, J. M., Fernández Roca, J. A. y Gómez Blanco, J. C. (eds.) (1994). Semiótica y Modernidad. Investigaciones Semióticas V. Actas del $V$ Congreso Internacional de la Asociación Española de Semiótica, vol. I. A Coruña: Universidade da Coruña.

PAZ GaGo, J. M. (ed.) (1994). Semiótica y Modernidad. Investigaciones Semióticas V. Actas del V Congreso Internacional de la Asociación Española de Semiótica, vol. 2. A Coruña: Universidade da Coruña.

ReAl PÉrez, B. (1994). «Un narrador galego da postmodernidade: A. Cunqueiro e As Crónicas do Sochantre». En Semiótica y Modernidad. Investigaciones Semióticas $V$. Actas del $V$ Congreso Internacional de la Asociación Española de Semiótica, Paz Gago, J. M. et al. (eds.), vol. 2, 249-254. A Coruña: Universidade da Coruña.

Rivas Monroy, M. U. (1994). «Ch. S. Peirce e G. Frege: a simplicidade da tríada». En Semiótica y Modernidad. Investigaciones Semióticas V. Actas del $V$ Congreso Internacional de la Asociación Española de Semiótica, Paz Gago, J. M. et al. (eds.), vol. 1, 217-224. A Coruña: Universidade da Coruña.

- (1996). «Frege y Peirce: en torno al signo y su fundamento». Anuario Filosófico 29/3, 1.211-1.224.

RODRíGUEZ FER, Cl. (ed.) (1992). Comentarios de textos contemporáneos. Vigo: Xerais. 
RODRÍGUEZ LÓPEZ-VÁZQUEZ, A. (1988). «El rol del influenciador: Lucifer según Robert de Niro». En Investigaciones Semióticas III. Actas del III Congreso Internacional de la Asociación Española de Semiótica. Madrid: UNED.

- (1990). Andrés de Claramonte. «Tan largo me lo fiáis» (Edición y reconstrucción del texto). Kassel: Reichenberger.

- (1992a). «Hipertelia y semiosis en la obra de Lezama Lima». En Investigaciones Semióticas IV. Actas del IV Congreso Internacional de la Asociación Española de Semiótica. Madrid: Visor.

- (1992b). «Mythe et sémiose. Don Juan Garañón/Don Juan Burlador». En Signs of Humanity/L'homme et ses signes, Deledalle, G., Balat, M. y Deledalle-Rhodes, J. (eds.), vol 2, 699-704. Berlín: Walter de Gruyter.

- (1992c). «Argumento mítico y creación teatral: de Lope de Vega a Alfonso Sastre». En Simposio O Teatro e o seu Ensino, 45-53. A Coruña: Universidade da Coruña.

- (1994). J. Laforgue: Moralidades legendarias (edición y estudio). Madrid: Cátedra.

- (1996a). «Psicoanálisis y literatura: la ficción como discurso», En Mundos de ficción, Actas del VI Congreso Internacional de la Asociación Española de Semiótica, Pozuelo, J. M. y Vicente, F. (eds.). Murcia: Universidad de Murcia.

- (1996b). «El ajedrez y la escritura pánica arrabaliana». En El teatro de vanguardia de Fernando Arrabal, 819-828. Kassel: Reichenberger.

- (1997a). «Zola, el naturalismo y el cine». En Literatura y Cine: Perspectivas Semióticas, Gómez Blanco, C. (ed.), 105-118. A Coruña: Universidade da Coruña.

- (1997b). «Geometría y humor en los cuentos de Bioy Casares». En El cuento hispanoamericano del siglo XX. Teoría y práctica, Valcárcel, E. (ed.), 325-338. A Coruña: Universidade da Coruña.

Rodríguez LóPez-VÁzquez, A. (ed.) (1992). O Teatro e o seu Ensino. A Coruña: Universidade da Coruña.

RODRf́gueZ VEGA, R. (1994). «La transformación paródica en la obra de Álvaro Cunqueiro». En Semiótica y Modernidad. Investigaciones Semióticas $V$. Actas del $V$ Congreso Internacional de la Asociación Española de Semiótica, Paz Gago, J. M. et al. (eds.), vol. 2, 259-268. A Coruña: Universidade da Coruña.

Romera CASTILlo, J. (1977). «Aspectos de una gramática semiótica de la poesía». En Crítica Semiológica, Bobes Naves, M. C. et al., 79-98. Oviedo: Universidad de Oviedo (1. ${ }^{\mathrm{a}}$ ed., Santiago: Universidad de Santiago de Compostela, 1974).

SUÁREZ BRIONES, B. (1996). «La verdad sospechosa bajo sospecha: de Ruiz de Alarcón a Pilar Miró». En Problemata Theatralia. El signo teatral: texto y representación, González Maestro, J. (ed.), 225-237. Vigo: Universidade de Vigo. 
TARRÍo VARELA, A. (1982). Lectura semiológica de Fortunata y Jacinta. Las Palmas: Cabildo Insular de Gran Canaria.

- (1987). De letras e de signos. Ensaios de semiótica e de crítica literaria. Vigo: Xerais.

- (1989). Álvaro Cunqueiro ou os disfraces da melancolía. Vigo: Galaxia.

- (1992). «O método semiótico: Deluvei os ollos, de Antón Tovar». En Comentarios de textos contemporáneos, Rodríguez $\mathrm{Fer}, \mathrm{Cl}$. (ed.), 6990. Vigo: Xerais.

- (1993a). «Álvaro Cunqueiro e as saídas do labirinto». En Congreso Álvaro Cunqueiro, 151-164. Santiago de Compostela: Xunta de Galicia.

- (1993b). «A investigación literaria en Galicia: A configuración do modelo de lector inmanente na Literatura Galega Contemporánea (18631991)». En Actas do I Simposium de Estudios Galegos/Proceedings of the 1st. Oxford Conference on Galician Studies, 81-92. Oxford: Xunta de Galicia.

VARela JÁCOME, B. (1956). Historia de la literatura gallega. Santiago: Porto Editores.

- (1967). Renovación de la novela en el siglo XX. Barcelona: Destino.

- (1973). Estructuras novelísticas de Emilia Pardo Bazán. Santiago de Compostela: Instituto Padre Sarmiento.

- (1974). Estructuras novelísticas del siglo XIX. Barcelona: Aubí.

- (1980). «Literatura Gallega». En Historia de Galicia. Barcelona: Planeta.

- (1982). «A estructura multiaxencial das Crónicas do Sochantre». En Homenaxe a Álvaro Cunqueiro. Santiago de Compostela: Universidade de Compostela.

- (1993). «Estratexias narrativas en Si o vello Simbad volvese ás illas». En Congreso Álvaro Cunqueiro, 165-174. Santiago de Compostela: Xunta de Galicia.

VAREla JACOME, B. y CARDONA, Á. (1980). Nuevas técnicas de análisis de textos. Madrid: Bruño.

- (1989). Poetología. Teoría y técnica de análisis de textos poéticos. Barcelona: PPU.

VIEITES, M. F. (1995). «Introducción 6 estudio do espacio do teatro». Revista Galega de Teatro 12.

- (1996). «Texto dramático, texto espectacular e texto teatral. Apuntamentos para unha teoría xeral da obra dramática». Anuario de Estudios Literarios Galegos 3, 103-125.

VIEITES, M. F. (ed.) (1997). Teoría e técnica teatral. Unha introducción. Santiago de Compostela: Laiovento.

VILAVEDRA, D. (1993a). Análise da polifonía na novela galega. Variabilidade diacrónica dos emisores textuais. Santiago: Universidade de Santiago de Compostela. Tesis inédita de doctorado.

- (1993b). «Polifonía e variabilidade diacrónica dos emisores inmanentes na novela galega». Anuario de Estudios Literarios Galegos 2, 131154. 
- (1994). «A Esmorga: Un exemplo de rendabilidade da polifonía como estratexia enunciativa nas literaturas minorizadas». En Semiótica y Modernidad. Investigaciones Semióticas V. Actas del V Congreso Internacional de la Asociación Española de Semiótica, Paz Gago, J. M. et al. (eds.), vol. 2, 421-434. A Coruña: Universidade da Coruña.

VILLANUEVA, D. (1977). Estructura y tiempo reducido en la novela. Valencia: Bello, 1977. (2 ed., Barcelona: Anthropos, 1994).

- (1984). «Narratario y lectores implícitos en la evolucion formal de la novela picaresca». En Estudios en honor a Ricardo Gullón, 343-367. Lincoln: Society of Spanish and Spanish-American Studies.

- (1986). «La novela picaresca y el receptor inmanente». Crítica Semiológica de Textos Literarios Hispánicos. Actas del Congreso Internacional Semiótica e Hispanismo, Garrido Gallardo, M. Á. (ed.), 96106. Madrid: C.S.I.C.

- (1986). «The Legacy of Jakobson's Linguistic Poetics». Poetics Today 7, 331-339.

- (1989). El comentario del texto narrativo. La novela. Gijón: Júcar.

- (1991a). El polen de ideas. Teoría, Crítica, Historia y Literatura Comparada. Barcelona: PPU.

- (1991b). «Phenomenology and the Pragmatics of Literary Realism». Analecta Husserliana 37, 217-235.

- (1992a). Teorías del realismo literario. Madrid: Instituto de EspañaEspasa Calpe.

- (1992b). «O método narratolóxico: O camiño de Quita e Pon, de Álvaro Cunqueiro». En Comentarios de textos contemporáneos, Rodríguez Fer, Cl. (ed.), 91-121. Vigo: Xerais.

- (1993). «A intencionalidade do realismo de Cunqueiro». En Congreso Álvaro Cunqueiro, 349-360. Santiago de Compostela: Xunta de Galicia.

- (1994). «1492-1992: Los signos del realismo». En Semiótica y Modernidad. Investigaciones Semióticas $V$. Actas del V Congreso Internacional de la Asociación Española de Semiótica, Paz Gago, J. M. et al. (eds.), vol. 1, 35-58. A Coruña: Universidade da Coruña.

- (1997). Theories of Literary Realism. New York: State University of New York Press.

VillanueVa, D. (ed.) (1994). Avances en Teoría de la Literatura (Estética de la Recepción, Pragmática, Teoría Empírica y Teoría de los Polisistemas). Santiago: Universidade de Santiago de Compostela. 